\title{
Investigating the Vinblastine Induced-Chromosomal Abnormality in the Already Gamma Irradiated L929 Cell Line Using Micronucleus Assay in Cytokinesis Blocked Binucleated Cells
}

\author{
Zahra Mohammadi ${ }^{1}$, Farhang Haddad ${ }^{1 *}$, Maryam M Matin², Shokouhozaman \\ Soleymanifard ${ }^{3}$
}

\begin{abstract}
Objectives: Vast number of studies show the relationship between aneuploidy and cancer. Ionizing radiation in addition to induce all kinds of damages to the cells and structure of chromosomes, is also able to induce aneuploidy through direct damages to chromosome division apparatus. Also irradiation of the cells induces mutations in several genes which might be involved in cell division fidelity and play a role in reversing the effect of aneugens. Therefore, irradiation of cells and tissues might produce sensitivity to agents with aneugenic capability in irradiated cells. Methods: To investigate the persistent genomic effect of ionizing irradiation on chromosomal instability, L929 cells were gamma irradiated with the dose of $2 \mathrm{~Gy}$. Cells were left to recover from the harmful effect of irradiation. They were treated with low dose of vinblastine (0.5 ng.ml-1) $72 \mathrm{~h}$ post-gamma irradiation. Finally, the induced chromosomal abnormalities were scored using micronucleus assay in cytokinesis-blocked binucleated cells (MnBi). Results: Irradiation-recovered L929 cells treated with vinblastine showed a statistically higher frequency of MnBi compared to non-irradiated and vinblastine treated cells. Conclusion: The results indicate that gamma irradiation, in addition to direct induction of chromosomal damages, is also able to create persisting genomic sensitivity in the cells to chromosomal instability, which is detectable when exposed to the second stimulus.
\end{abstract}

Keywords: Gamma irradiation- Vinblastine- Micronucleus assay- L929 cell

Asian Pac J Cancer Prev, 20 (4), 1045-1050

\section{Introduction}

Aneuploidy is the result of chromosome malsegregation during cell division. Aneuploid cells gain or loss one or more chromosome(s). Aneuploidy is responsible for a wide range of problems in human life. It is the main cause for many abortions, newborn abnormalities, sterility (Hassold et al., 2007), and cancer (Cimini and Degrassi, 2005). The important role of aneuploidy in cancer has been suggested in many studies (Duesberg and Li, 2003; Gordon et al., 2012; Giam and Rancati, 2015).

Aneuploidy, by unbalancing the expression of several genes, induces tumor formation through disturbing the cell equilibrium. Damages to the cells normal status, in turn, induce more abnormal chromosome segregation during cell divisions (Passerini and Storchova, 2016). The relationship between aneuploidy and cancer is so strong that it is suggested to be used as a biomarker for integrated chemical assessments of carcinogenicity (Mandrioli et al.,
2016). The proposed relationship between aneuploidy and cancer explains why some cancers are caused by non-mutagenic carcinogens and are chromosomally unstable (Duesberg et al., 2006). Investigating the reasons for the induction of aneuploidy is the interest of many studies. The more understanding about aneuploidy, the more effective therapeutic procedures would be developed (Tanaka and Hirota, 2016). Environmental stimuli with a positive effect on aneuploidy induction are being studied in mutagenesis investigations (Jin et al., 2015).

Ionizing radiation has always been known as a strong clastogenic factor. Moreover, in some studies, its aneugenic effect has also been suggested. The results of different experiments show that in addition to clastogenic effect, it is also able to induce aneuploidy in irradiated cells (Ponsa, 2001; Tateno et al., 2011; Cho et al., 2015). Ionizing radiation directly induces chromosome malsegregation through imposition damages to spindle poles and centrosome integrity (Sgura, 2001; Maxwell et 
al., 2008). It might be also able to induce damages to the genes involved in chromosome segregation during cell cycles. These damages are created through its mutagenic capability, mediated by induced oxidative stress, which indirectly leads to aneuploidy (Ikawa-Yoshida et al., 2013).

The risk of the second tumor formation is considerably high in cancer treatment protocols, which include radiotherapy (Imaoka et al., 2016). The susceptibility of cancer patients, who have received radiation, to the increased risk of second cancer suggests the higher sensitivity of the irradiated normal cells to other stimuli capable to induce genomic instability.

To study the indirect effect of ionizing radiation in chromosome malsegregation, we investigate the fidelity of chromosome segregation in the cells recovered from gamma-irradiation using a known strong aneugen, vinblastine.

\section{Materials and Methods}

\section{Cell line}

The L929 cell line, passage 13-15, was used in this experiment. The cells were cultured in LG DMEM (Gibco) completed with $10 \% \mathrm{FBS}$ (Gibco) and left in $37^{\circ} \mathrm{C}$ and $5 \%$ $\mathrm{CO}_{2}$ until needed. Cells were sub-cultured every $72 \mathrm{~h}$ in the ratio of 1 to 5. Cell culture was performed in duplicate for each treatment and its corresponding control.

\section{Irradiation}

Gamma irradiation of the cells with the rate of 0.99Gy. Min-1 was performed $24 \mathrm{~h}$ post culture initiation at the final dose of $2 \mathrm{~Gy}$ in T25 flask (60Co radiation therapy, Therateron, Canada). Irradiated cells, as well as controls, were harvested $24,48,72$, and $96 \mathrm{~h}$ post-irradiation. Culture medium replacement was gently performed at $72 \mathrm{~h}$ post-culture initiation only for the culture harvested $96 \mathrm{~h}$ post-irradiation.

\section{Vinblastine treatment}

Vinblastine sulfate (Gedeon Ichter Ltd.) was dissolved in distilled water to the final concentration of $1 \mu \mathrm{g} \cdot \mathrm{ml}^{-1}$. Cells were treated with two doses of 0.5 and $1.5 \mathrm{ng} \cdot \mathrm{ml}^{-1}$ of vinblastine for $24 \mathrm{~h}$. When needed, the vinblastine treatment was performed $72 \mathrm{~h}$ after irradiation with a dose of $0.5 \mathrm{ng} . \mathrm{ml}-1$ for further $24 \mathrm{~h}$. The culture medium was gently replaced with a medium containing cytochalasin-B after this period. During the entire experiment time, sub-culturing was performed every $72 \mathrm{~h}$.

\section{Cell harvest}

Cell harvest was performed according to suggested procedure (Fenech, 2000) with slight modifications. Cytochalasin-B with the final concentration of $4 \mu \mathrm{g} . \mathrm{ml}-1$ was added to the cultures $20 \mathrm{~h}$ before harvest. Cells were centrifuged and washed twice with fixator of 9:1 methanol: acetic acid. Few cell drops were placed on the clean microscopic slides and left aside to air dry.

Slides were stained using 20\% Giemsa for $20 \mathrm{~min}$.

\section{Scoring}

Scoring took place at a $1,000 x$ magnification. In this study, cells with two detached nuclei were scored as a binucleated cell (Bi). For each treatment and control, at least three slides were coded, and on each slide, at least $500 \mathrm{Bi}$ were blindly scored. In all Bi scored, cells harboring small unattached nucleus were considered as a micronucleated binucleate cell $(\mathrm{MnBi})$. The frequency of $\mathrm{MnBi}$ in each treatment and control was calculated as:

Frequency of $M n B i=$ Number of $M n B i /$ Total Number of Bi scored

MTT assay

Irradiated cells, as well as untreated control cells, were cultured in 96 wells culture plates. Cell viability test was performed for control and irradiated cells harvested 24, 48, 72, and 96h post-irradiation. Next, $100 \mu \mathrm{g}$ of a tetrazolium salt (Sigma), dissolved in PBS, was added to $200 \mu \mathrm{l}$ of cell culture medium and left for $6 \mathrm{~h}$ in $37^{\circ} \mathrm{C}$. The medium of each well was discarded and $150 \mu 1$ of DMSO was added to each well. Light absorbance of each well at $545 \mathrm{~nm}$ wavelength was recorded using Eliza reader (AWASENESS). The light absorbance value of each well was compared to that of the control and its graph was prepared.

\section{Statistical analysis}

The statistical analysis was performed using software MINITAB version 14. The differences between treated and control groups and also between treated groups were analyzed by one-way analysis of variance (ANOVA).

\section{Results}

Vinblastine treatment:Data for vinblastine treatment are presented in Figure 1. Treating the L929 cells with two different doses of vinblastine significantly increased the frequency of $\mathrm{MnBi}$ compared to control $(\mathrm{P}<0.01)$. The dose of 1.5ng.ml-1 of vinblastine showed a stronger effect in inducing Mn compared to 0.5 ng.ml-1 $(\mathrm{P}<0.01)$.

\section{Gy Gamma irradiation and cell recovery}

The L929 cells were treated with 2Gy Gamma irradiation and harvested at different time points. Figure 2 shows the time-dependent reduction of Mn frequency in irradiated cells. The highest frequency of MnBi was at $48 \mathrm{~h}$ post-treatment. At $72 \mathrm{~h}$ after irradiation, the frequency of $\mathrm{MnBi}$ was back to the normal baseline and showed no significant differences with control.

The cell viability of gamma-irradiated cells was also analyzed (Figure 3). Irradiated cells showed a significant decrease in cell viability at $24 \mathrm{~h}$ post-irradiation and a time-dependent cell recovery occurred. Cells were significantly recovered and backed to normal percent of viability at $72 \mathrm{~h}$ post-irradiation.

\section{Vinblastine treatment of Irradiated cells}

Data of different treatment combination of the L929 cells are shown in Fig. 4. Cells treated with 0.5 ng. $\mathrm{ml}^{-1}$ vinblastine showed a significantly higher frequency of $\mathrm{MnBi}$ compared to that of the control $(\mathrm{P}<0.01)$. However, 


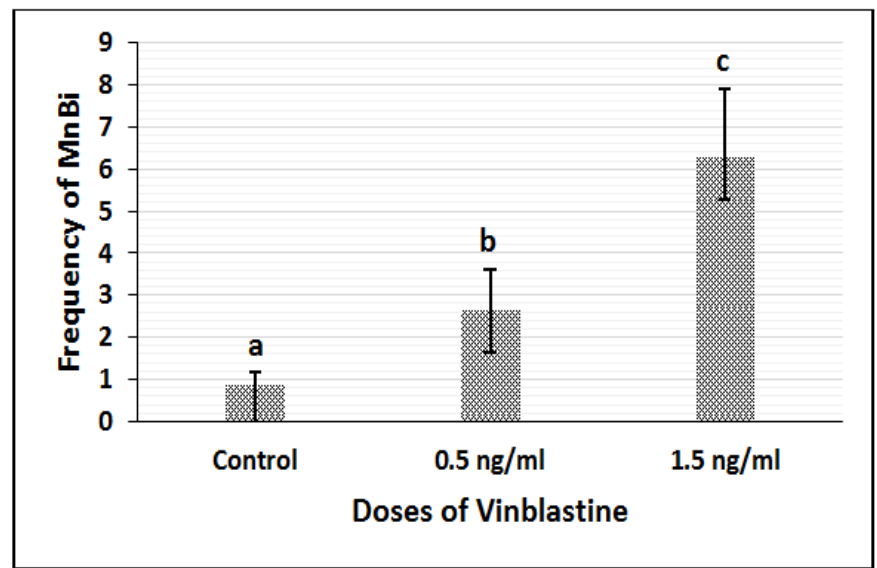

Figure 1. Frequency of MnBi in Cells Treated with Two Doses of Vinblastine. a, b, c statistical differences between groups $(\mathrm{P}<0.01)$

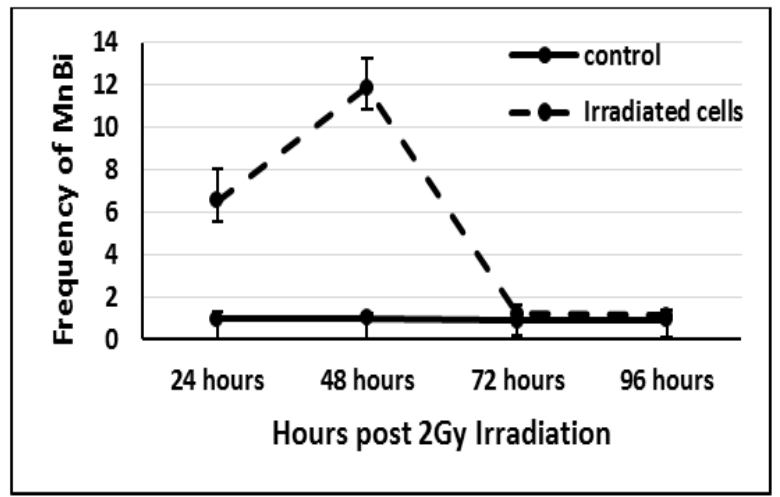

Figure 2. Recovery of the Cells after 2 Gy Gamma Irradiation.

Cells recovered after $72 \mathrm{~h}$ from 2 Gy Gamma irradiation showed no increase in the frequency of MnBi compared to control. Treatment of $72 \mathrm{~h}$ post-irradiation recovered cells with a 0.5 ng.ml- 1 dose of vinblastine significantly induced the frequency of $\mathrm{MnBi}$ compared to control as well as other treatments.

\section{Discussion}

Aneuploidy is the result of chromosome malsegregation during cell division. Cancer cells exhibit some sort of

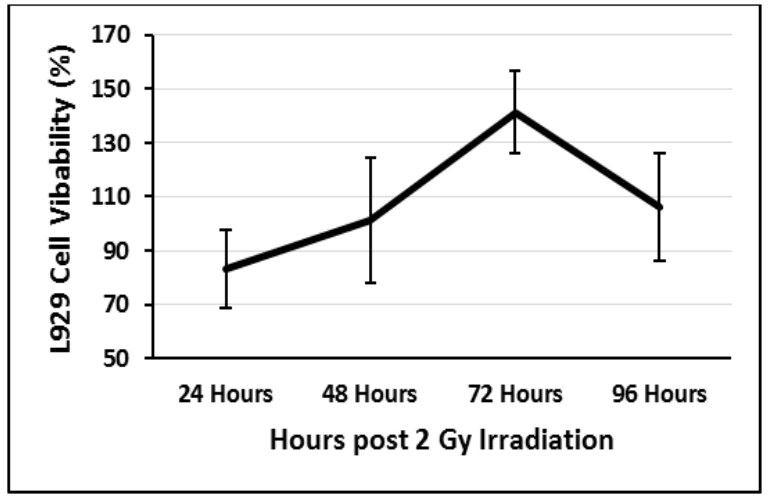

Figure 3. L929 Cells Viability at Different Time Interval after 2 Gy Gamma Irradiation

aneuploidy and their severity is associated with the degree of cancer (Sen, 2000; Duesberg et al., 2006). Due to the proposed important role of aneuploidy in tumor formation and cancer (Devi and Satyamitra, 2005; Mandrioli et al., 2016), studying the causes behind aneuploidy formation and potential triggering factors of aneuploidy is of paramount importance. Studies show that ionizing radiation in addition to its clastogenic effect is able to induce aneuploidy (Maxwell et al., 2008; Jin et al., 2015). Its ability to cause chromosome loss or nondisjunction is believed to be the result of direct damages to chromosome

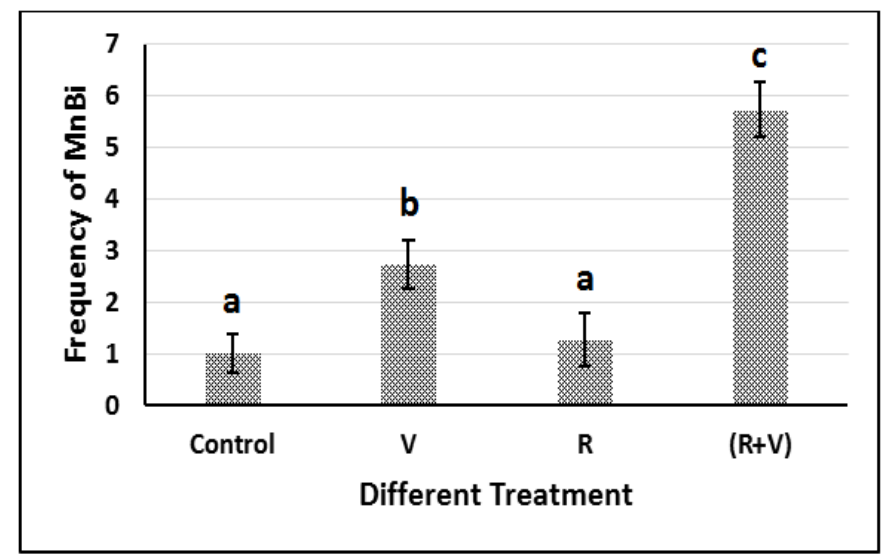

Figure 4. Frequency of MnBi in Different Treatments. R, Recovered cells 72 hours post-irradiation; V, Vinblastine treated cells. a, b, c statistical differences between groups $(\mathrm{P}<0.01)$ 
segregation apparatus and deregulating the centrosome synthesis during cell division (Maxwell et al., 2008).

Irradiation-induced aneuploidy at several cell cycle post irradiation has not been investigated in other studies. In the present work, we investigated the effect of persisting genetic damages caused by ionizing radiation in chromosome instability during cell division. The clastogenic ability of ionizing radiation has been established in several studies. Irradiation can cause chromatid/chromosome breaks in treated cells as a result of its direct effect on DNA or by producing free radical capable of interacting with DNA and finally causing breaks in chromosomes (Suto et al., 2015; Pathak et al., 2016). In this study, 2 Gy gamma irradiation resulted in a significant increase in $\mathrm{MnBi}$, with the highest frequency at $48 \mathrm{~h}$ post-irradiation. The increase in the frequency of $\mathrm{MnBi}$ was the result of increased levels of breaks in chromosomes structure, which could be seen as micronucleus in binucleated cells. Gamma irradiation of human lymphocytes in vitro also increased the centromere-negative micronuclei, which indicate the clastogenic capability of gamma irradiation (Vral et al., 1997). One Gy Gamma irraidaiton of TK6 human lymphoblastoid cell line also led to the almost same frequency of micronuclei binucleated cells as our study (Yamamoto et al., 2017).

When micronuclei-inducing stimuli are removed, the induced micronuclei will be unstable and their frequency will be reduced because of either losing them during cell divisions or integration into main nuclei (Leach and Jackson-Cook, 2004). In this study, the frequency of Gamma-induced micronuclei backed to normal $72 \mathrm{~h}$ post-irradiation. Twenty-four hours after that, no increase in the frequency of $\mathrm{MnBi}$ was detected, suggesting that cells were in some equilibrium after a harmful event. Also, cell viability analysis confirms the ability of the cells to recover from the harmful effect of gamma irradiation after $72 \mathrm{~h}$ and maintain the same percent of viable cells as untreated cells. Time-response investigation of gamma-irradiated human lymphoblastoid also showed an increase and decrease in the frequency of micronucleus at first and the third cell cycle post-irradiation, respectively (Ramirez et al., 1999). The cell cycle time of the L929 cells is 36 hours (Baca et al., 1985). So, in our experiment the L929 cells showed and increase and decrease of micronucleus at first and second cell cycle respectively. The time response difference between our data and the result of that study could be related to the higher ability of L929 cells to adapt with any disturbances compared to human lymphoblastoid cell lines. Parasidic infection of L929 cells also did not change the cell cycle time (Baca et al., 1985).

In this study, the chromosome instability was induced by vinblastine (C46H58N4O9), which is a Vinca alkaloid with the confirmed aneugenic potential in several in vitro and in vivo studies (Leopardi et al., 2002; Cammerer et al., 2010). Its aneugenic ability even at low doses has been already confirmed (Huber et al., 1996; Marshall et al., 1996; Zijno et al., 1996). Treatment of the cells with vinblastine in this study also led to an increase in $\mathrm{MnBi}$ frequency. Due to the aneugenic capability of vinblastine, the increased level of $\mathrm{Mn}$ in treated cells with two doses of vinblastine was probably related to the whole chromosome loss during cell divisions. Micronucleus assay in binucleated cells would reveal the chromosome loss for the whole or a part of the chromosome as micronucleus in the cytoplasm. In this regard, the only way to distinguish the Mn caused by whole chromosome loss or part of the chromosome is to perform centromere labeling either by centromeric DNA probes or by antikinetochore antibodies. In many studies, treating the cells with different doses of vinblastine has been led to significant increase in centromere positive Mn which suggested induced chromosome loss and aneuploidy in those cells (Huber et al., 1996; Marshall et al., 1996; Zijno et al., 1996).

Treating the cells recovered from gamma irradiation with vinblastine led to the statistically significant increase in the frequency of $\mathrm{MnBi}$ compared to the vinblastine treated /non-irradiated cells. This increase shows the susceptibility of the irradiated cells to the aneugenic activity of vinblastine. Although the irradiated cells seem to be recovered from chromosomal effects of irradiation, judged by baseline frequency of $\mathrm{MnBi}$, but they seem to be genetically damaged. Such damages result in a higher sensitivity of the cells to vinblastine treatment so that it is able to induce chromosome segregation irregularity in these cells more profoundly.

Several genes are involved in controlling the fidelity of chromosome segregation during cell division such as BUB3, AURKA, DYNC1I1, DCTN2, and CHFR. Any mutations or changes in these genes, which might influence their expression or function of their product, will lead to malsegregation of chromosomes such as loss and non-disjunction (Ertych et al., 2016; Krause et al., 2016). Mutation in BUB3, an important member of spindle assembly checkpoint, leads to mosaic aneuploidy in affected individuals and a higher risk of colorectal cancer (de Voer et al., 2013).

In addition to its clastogenic damages to genetic material, ionizing irradiation is able to induce gene mutations in irradiated cells (Adewoye et al., 2015; Shahid et al., 2015). As other genes in the cells, the ones involved in chromosome segregation and those involved in controlling cell division fidelity might be targeted by the ionizing irradiation. These mutated genes could not perform their duty during cell division. In these cells when there are no harmful stimuli which might lead to chromosome loss or non-disjunction, no disruption in chromosome migration is monitored. However, when treated with second agent capable to induce chromosomal malsegregation, mutated genes involved in cell division fidelity are unable to perform their duties. Thus, vinblastine treatment of irradiated cells induced the higher frequency of chromosome loss compared to the normal cells, which were represented as a higher frequency of $\mathrm{MnBi}$.

In conclusion, the data of this study suggest that 2 Gy gamma irradiation not only has the main effect on genetic material seen as chromosomal abnormalities but also has subtle effects on genes involved in the division, which could sensitize the cells to other stimuli later in their 
life cycles. This finding has great importance in cases of radiation therapy and other procedures involved in cancer treatment. It has to be noted that cells of irradiated tissues might be more sensitive to other chemicals capable of inducing chromosome malsegregation. Such susceptibility would explain the high risk of second tumor formation in patient undergone radiotherapy.

\section{Conflict of Interest}

The authors report no conflicts of interest.

\section{Acknowledgements}

This work was financially support by the Grant from Ferdowsi University of Mashhad, Iran from the project no. $3 / 22396$

\section{References}

Adewoye AB, Lindsay SJ, Dubrova YE, et al (2015). The genome-wide effects of ionizing radiation on mutation induction in the mammalian germline. Nat Commun, 6, 6684.

Baca OG, Scott TO, Akporiaye ET, et al (1985). Cell cycle distribution patterns and generation times of L929 fibroblast cells persistently infected with Coxiella burnetii. Infect Immun, 47, 366-9.

Cammerer Z, Schumacher MM, Kirsch-Volders M, et al (2010). Flow cytometry peripheral blood micronucleus test in vivo: determination of potential thresholds for aneuploidy induced by spindle poisons. Environ Mol Mutagen, 51, 278-84.

Cho YH, Kim SY, Woo HD, et al (2015). Delayed numerical chromosome aberrations in human fibroblasts by low dose of radiation. Int J Environ Res Public Health, 12, 15162-72.

Cimini D, Degrassi F (2005). Aneuploidy: a matter of bad connections. Trends Cell Biol, 15, 442-51.

de Voer RM, Geurts van Kessel A, Weren RD, et al (2013). Germline mutations in the spindle assembly checkpoint genes BUB1 and BUB3 are risk factors for colorectal cancer. Gastroenterology, 145, 544-7.

Devi PU, Satyamitra M (2005). Tracing radiation induced genomic instability in vivo in the haemopoietic cells from fetus to adult mouse. Br J Radiol, 78, 928-33.

Duesberg P, Li R (2003). Multistep carcinogenesis: a chain reaction of aneuploidizations. Cell Cycle, 2, 202-10.

Duesberg P, Li R, Fabarius A, et al (2006). Aneuploidy and cancer: from correlation to causation. In 'Infection and inflammation: impacts on oncogenesis', Eds Karger Publishers, pp 16-44.

Ertych N, Stolz A, Valerius O, et al (2016). CHK2-BRCA1 tumor-suppressor axis restrains oncogenic Aurora-A kinase to ensure proper mitotic microtubule assembly. Proc Natl Acad Sci US A, 113, 1817-22.

Fenech M (2000). The in vitro micronucleus technique. Mutat Res-Fund Mol M J, 455, 81-95.

Giam M, Rancati G (2015). Aneuploidy and chromosomal instability in cancer: a jackpot to chaos. Cell Div, 10, 3 .

Gordon DJ, Resio B, Pellman D (2012). Causes and consequences of aneuploidy in cancer. Nat Rev Genet, 13, 189-203.

Hassold T, Hall H, Hunt P (2007). The origin of human aneuploidy: where we have been, where we are going. Hum Mol Genet, 16, 203-8.

Huber R, Salassidis K, Kulka U, et al (1996). Detection of centromeres in vinblastine-and radiation-induced micronuclei of human lymphocytes using FISH with an $\alpha$ satellite pancentromeric DNA probe. Environ Mol Mutagen,
27, 105-9.

Ikawa-Yoshida A, Ando K, Oki E, et al (2013). Contribution of BubR1 to oxidative stress-induced aneuploidy in p53-deficient cells. Cancer Med, 2, 447-56.

Imaoka T, Ishii N, Kawaguchi I, et al (2016). Biological measures to minimize the risk of radiotherapy-associated second cancer: A research perspective. Int J Radiat Biol, 92, 289-301.

Jin H, Yoon HE, Lee JS, et al (2015). Effects on g2/m phase cell cycle distribution and aneuploidy formation of exposure to a $60 \mathrm{~Hz}$ electromagnetic field in combination with ionizing radiation or hydrogen peroxide in 1132 nontumorigenic human lung epithelial cells. Korean J Physiol Pharmacol, 19, $119-24$

Krause L, Nones K, Loffler KA, et al (2016). Identification of the CIMP-like subtype and aberrant methylation of members of the chromosomal segregation and spindle assembly pathways in esophageal adenocarcinoma. Carcinogenesis, 37, 356-65.

Leach NT, Jackson-Cook C (2004). Micronuclei with multiple copies of the X chromosome: do chromosomes replicate in micronuclei?. Mutat Res, 554, 89-94.

Leopardi P, Marcon F, Dobrowolny G, et al (2002). Influence of donor age on vinblastine-induced chromosome malsegregation in cultured peripheral lymphocytes. Mutagenesis, 17, 83-8.

Mandrioli D, Belpoggi F, Silbergeld EK, et al (2016). Aneuploidy: a common and early evidence-based biomarker for carcinogens and reproductive toxicants. Environ Health, $15,97$.

Marshall RR, Murphy M, Kirkland DJ, et al (1996). Fluorescence in situ hybridisation with chromosome-specific centromeric probes: a sensitive method to detect aneuploidy. Mutat ResFund Mol M J, 372, 233-45.

Maxwell CA, Fleisch MC, Costes SV, et al (2008). Targeted and nontargeted effects of ionizing radiation that impact genomic instability. Cancer Res, 68, 8304-11.

Passerini V, Storchova Z (2016). Too much to handle - how gaining chromosomes destabilizes the genome. Cell Cycle, 15, 2867-74.

Pathak R, Bachri A, Ghosh SP, et al (2016). The Vitamin E analog Gamma-Tocotrienol (GT3) suppresses radiation-induced cytogenetic damage. Pharm Res, 33, 2117-25.

Ponsa I BJ, Miró R, Egozcue J, Genescà A (2001). Non-disjunction and chromosome loss in gamma-irradiated human lymphocytes: A fluorescence in situ hybridization analysis using centromere-specific probes. Radiat Res, 155, 424-31.

Ramirez MJ, Surralles J, Puerto S, et al (1999). Low persistence of radiation-induced centromere positive and negative micronuclei in cultured human cells. Mutat Res, 440, 163-9.

Sen S (2000). Aneuploidy and cancer. Curr Opin Oncol, 12, 82-8.

Sgura A AA, Cherubini R, Tanzarella C, (2001). Chromosome nondisjunction and loss induced by protons and $\mathrm{X}$ rays in primary human fibroblasts: Role of centromeres in aneuploidy. Radiat Res, 156, 225-31.

Shahid S, Nawaz Chaudhry M, Mahmood N, et al (2015). Mutations of the human interferon alpha-2b gene in brain tumor patients exposed to different environmental conditions. Cancer Gene Ther, 22, 246-61.

Suto Y, Akiyama M, Noda T, et al (2015). Construction of a cytogenetic dose-response curve for low-dose range gamma-irradiation in human peripheral blood lymphocytes using three-color FISH. Mutat Res Genet Toxicol Environ Mutagen, 794, 32-8.

Tanaka K, Hirota T (2016). Chromosomal instability: A common feature and a therapeutic target of cancer. Biochim Biophys Acta, 1866, 64-75. 
Tateno H, Kusakabe H, Kamiguchi Y (2011). Structural chromosomal aberrations, aneuploidy, and mosaicism in early cleavage mouse embryos derived from spermatozoa exposed to gamma-rays. Int $J$ Radiat Biol, 87, 320-9.

Vral A, Thierens H, De Ridder L (1997). In vitro micronucleus-centromere assay to detect radiation-damage induced by low doses in human lymphocytes. Int $J$ Radiat Biol, 71, 61-8.

Yamamoto A, Hirouchi T, Kawamorita S, et al (2017). Radioprotective activity of blackcurrant extract evaluated by in vitro micronucleus and gene mutation assays in TK6 human lymphoblastoid cells. Genes Environ, 39, 22.

Zijno A, Marcon F, Leopardi P, et al (1996). Analysis of chromosome segregation in cytokinesis-blocked human lymphocytes: non-disjunction is the prevalent damage resulting from low dose exposure to spindle poisons. Mutagenesis, 11, 335-40.

This work is licensed under a Creative Commons AttributionNon Commercial 4.0 International License. 